\title{
Gender Differences in Child Health-care Practices: Evidence from the Pakistan Demographic and Health Survey, 1990-91
}

\author{
NAUSHIN MAHMOOD and MiR ANNICE MAHMOOD
}

\section{INTRODUCTION}

Among other factors, health care utilisation is important in determining the health status and survival chances of children. The patterns of childhood mortality, in general, indicate that deaths of male children have consistently exceeded those of females, with a much greater difference in the first month of birth (NNR). This has largely been attributed to differences in the genetic and biological factors between the sexes [Lopez and Ruzika (1983)]. The mortality level, thereafter, is influenced more by the socio-economic, environmental, and health care factors, indicating a mortality disadvantage for females in some populations. It has therefore been postulated that gender-based differences in health care practices partly explain the sex differentials in child mortality in some countries of South Asia, where healthseeking behaviour of parents discriminates against female children [Chen, et al. (1981); Das Gupta (1987); Sathar (1987); Ahmed (1990)].

Using data from Bangladesh, Chen, Haq, and D’Souza (1981) found that girls' mortality risk was nearly 60 percent higher than that for boys after the neonatal period, and that girl children suffered more malnutrition and received lesser treatment for various infections. Das Gupta (1987) and Muhuri and Preston (1991) also explained the excess mortality of girls with a surviving elder sister in terms of conscious, selective neglect of the second daughter. Waldron (1983) in her extensive review of child mortality patterns in developing countries concluded that besides relative contributions of specific causes of death with different impact by sex, the variability in discrimination by gender, primarily in nutrition and health care utilisation, also contributes to excess female child mortality (1-4 age group).

However, a study on Karachi [Alizai and Zia (1990)] found no perceived differentiation in taking a sick child for treatment to a doctor/hospital, and little awareness of gender bias in the attitudes or behaviour of parents and professionals regarding the health care of children. Porapakkam (1983), looking at selected case

Naushin Mahmood is Senior Research Demographer and Mir Annice Mahmood is Senior Faculty Member at the Pakistan Institute of Development Economics, Islamabad. 
studies, found for Thailand that the incidence rate of morbidity was higher for female than male children, but no gender differentials were apparent in the use and non-use of specific health facilities.

Recognising the fact that child health care practices are the proximate factors in child mortality, the objectives of this paper are to ascertain whether sex differences exist in under-five mortality, as well as to determine whether gender differences are apparent in the health status, morbidity incidence, and preventive and curative treatment of disease among children. The paper also explores some of the potential gender dimensions of female mortality disadvantage during childhood.

\section{DATA AND METHODS}

For the purposes of this analysis, we use data from the Pakistan Demographic and Health Survey of 1990-91, which has collected extensive information on fertility, child mortality, and child health indicators. The survey provides a full birth history of each woman with the date of birth and the sex and age at death of each child, making it possible to estimate child mortality and health care indicators by sex. Among the health care indicators, data on factors such as immunisation, morbidity rates for fever, cough, respiratory infections, and diarrhea are available, with information on whether any treatment to the child was given or not during sickness.

The sample selected for the present analysis is the number of all children born during the five years preceding the survey date (all births occurring since January 1986), for which information on each child's survival, health care, and morbidity status is available.

For mortality measures, neonatal, infant, and child mortality rates are used to examine changes in the levels of mortality over time. The proportion of children dead in a particular category is also described to indicate the differentials by sex in relation to selected socio-economic factors. For health care indicators, the measure used is generally the absolute differences between the percentages of female and male children (under five years of age) with a particular characteristic.

\section{PAST EVIDENCE ON SEX DIFFERENTIALS IN INFANT/CHILD MORTALITY}

The estimates of child mortality from various data sources indicate that the overall levels of childhood mortality have declined in Pakistan ${ }^{1}$ (Table 1). Girls' infant mortality rate has considerably declined from 102 during 1984-88 to 80 per thousand live births during the 1986-91 period. The corresponding rates for boys are from 116 to 101 per thousand live births. The change in infant mortality is largely

${ }^{1}$ This is also reflected in terms of improvements in the expectation of life at birth in recent years. It appears that health interventions have increased the rate of decline of female mortality more than that of males. 
attributable to improvements in postneonatal mortality, while neonatal mortality disfavours boys, who have nearly 30 percent higher deaths than females in the 198691 period. However, child mortality (1-4 years) remains higher among girls than boys over the past years, indicating a female disadvantage in child mortality. This may be suggestive of some gender-related differences in child-rearing and health care practices that favour boys more than girls.

Table 1

Infant and Child Mortality Rates by Gender from Various Surveys

\begin{tabular}{|c|c|c|c|c|c|c|c|c|}
\hline \multirow{2}{*}{$\begin{array}{l}\text { Childhood } \\
\text { Mortality }\end{array}$} & \multicolumn{2}{|c|}{$1965-79^{\mathrm{a}}$} & \multicolumn{2}{|c|}{$1976-79^{b}$} & \multicolumn{2}{|c|}{$1984-88^{\mathrm{C}}$} & \multicolumn{2}{|c|}{$1986-91^{\mathrm{d}}$} \\
\hline & Boys & Girls & Boys & Girls & Boys & Girls & Boys & Girls \\
\hline $\begin{array}{l}\text { Neonatal } \\
(<1 \text { Month) }\end{array}$ & 79 & 70 & - & - & 67 & 54 & 59 & 44 \\
\hline $\begin{array}{l}\text { Infant Mortality } \\
\text { (0-11 Months) }\end{array}$ & 120 & 117 & 102 & 86 & 116 & 102 & 101 & 80 \\
\hline $\begin{array}{l}\text { Child Mortality } \\
\text { (1-4 Years) }\end{array}$ & 44 & 48 & 39 & 46 & 27 & 29 & $22 *$ & $37 *$ \\
\hline
\end{tabular}

Source: ${ }^{*}$ The rates are for the ten-year period preceding the survey, (1981-91).

${ }^{a}$ Population, Labour Force and Migration Survey, as quoted in Sathar (1987).

${ }^{\mathrm{b}}$ Population Growth Survey, as quoted in Afzal (1988).

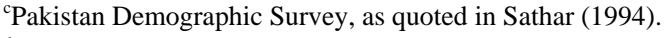

${ }^{\mathrm{d}}$ Pakistan Demographic and Health Survey, 1990-91.

\section{RESULTS FROM THE PDHS}

\section{Sex Differences in Child Mortality}

A more detailed examination of the PDHS data shows that out of the total births during the five years preceding the survey (6558), 8.6 percent died, and 91.4 percent survived. Of the total number of deaths (563), the proportion of boys is higher (53 percent) than of girls (47 percent). The distribution of deaths is given in Table 2, which shows that nearly 86 percent of the deaths occurred during infancy, while 14 percent between the ages of $1-4$ years. The proportion of deaths is the highest for boys in the first month of life (50.2 percent as compared to 46.6 percent for girls). In the later months (1-11 and 12-48), the proportion is higher for girls than for boys.

Results from research studies and the National Health Survey indicate that the major causes of death during infancy are acute respiratory infections, diarrhea, and malnutrition [Ahmed (1990)]; these also suggest that better facilities in the household and health care practices tend to improve the health status and survival chances of children [Government of Pakistan (1986); Mahmood and Kiani (1994)]. 
Table 2

Percentage Distribution of Child Deaths by Gender and by Age at Death, and Social Status Indicators: PDHS, 1990-91

\begin{tabular}{|c|c|c|c|c|c|c|}
\hline \multirow[b]{2}{*}{ Total } & \multicolumn{2}{|c|}{ Boys } & \multicolumn{2}{|c|}{ Girls } & \multicolumn{2}{|c|}{ Total Deaths } \\
\hline & $\%$ & $(\mathrm{~N})$ & $\%$ & $(\mathrm{~N})$ & $\%$ & $(\mathrm{~N})$ \\
\hline Total Deaths & 53.1 & (299) & 46.9 & (264) & 100.0 & (563) \\
\hline \multicolumn{7}{|l|}{ Age at Death } \\
\hline$<1$ Month & $50 \cdot 2$ & (150) & $46 \cdot 6$ & (123) & $48 \cdot 5$ & (273) \\
\hline 1-11 Months & $36 \cdot 5$ & (109) & $39 \cdot 0$ & (103) & $37 \cdot 7$ & (212) \\
\hline 12-48 Months & $13 \cdot 4$ & $(40)$ & $14 \cdot 4$ & (38) & $13 \cdot 9$ & (78) \\
\hline \multicolumn{7}{|l|}{ Residence } \\
\hline Urban & $47 \cdot 2$ & (141) & $50 \cdot 4$ & (133) & $48 \cdot 7$ & (274) \\
\hline Rural & $52 \cdot 8$ & (158) & $49 \cdot 6$ & (131) & $51 \cdot 3$ & (289) \\
\hline \multicolumn{7}{|l|}{ Women's Age } \\
\hline$<30$ & $69 \cdot 9$ & (209) & 68.9 & (182) & $69 \cdot 4$ & (391) \\
\hline $30+$ & $30 \cdot 1$ & (90) & $31 \cdot 1$ & (182) & $30 \cdot 6$ & (172) \\
\hline \multicolumn{7}{|l|}{$\begin{array}{l}\text { Women's } \\
\text { Education }\end{array}$} \\
\hline None & $81 \cdot 6$ & (244) & $81 \cdot 8$ & (216) & $81 \cdot 7$ & (460) \\
\hline Some & $18 \cdot 4$ & $(55)$ & $18 \cdot 2$ & (48) & $18 \cdot 3$ & (103) \\
\hline
\end{tabular}

High risks of infant and child deaths are generally found among families of low socio-economic status. Higher family income, mother's education, and urban residence usually taken as indicators of better nutrition, and greater awareness and access to health facilities, are likely to reduce child mortality risks [Alam and Cleland (1984); Ahmed (1992)]. Based on the PDHS data, the proportion of child deaths by selected social status indicators, such as urban residence and mother's education, is shown in Table 2. The figures support the negative association of urban residence and education with child mortality. Nearly 18 percent of the deaths are experienced by educated mothers as compared to 82 percent for women with no education.

\section{Gender Differentials in Child Morbidity and Curative Measures}

The two diseases most prevalent among children in Pakistan are acute respiratory infections, indicated by cough with fast or difficult breathing, and diarrhea. The PDHS provided information on these specific diseases as cough, 
fever, and diarrhea prevalent among children under five years of age in some reference period, typically two weeks before the survey. It should be noted that the data on morbidity and the use of health services are for surviving children only, who are 91.4 percent of the total births selected for this study. Hence, even with the deaths removed, the distribution of survivors would quite reasonably reflect health status differentials.

Table 3 presents the percentages of the girls and boys sick with fever, cough, and diarrhea during the past two weeks preceding the survey date. Overall, it appears that girls are slightly less likely to be sick (as reported sick by their mothers) than boys. Out of the total children sick with fever (1683), and cough (1911), nearly 52 percent are boys and 48 percent are girls. The number of children reported as sick with diarrhea is much lower than the incidence of fever and cough. However, their distribution by gender again shows a slightly higher proportion of boys with diarrheal infections both during the past two weeks and within 24 hours of the survey date. The table shows that nearly 54 percent of the boys are reported sick with diarrhea within the past 24 hours as compared to 45 percent of the girls.

Table 3

Morbidity Prevalence among Children (under five) Two Weeks Preceding the Survey, and the Curative Measures by Gender: PDHS, 1990-91

\begin{tabular}{|c|c|c|c|c|c|c|}
\hline \multirow[b]{2}{*}{ Type of Disease } & \multicolumn{2}{|c|}{ Boys } & \multicolumn{2}{|c|}{ Girls } & \multicolumn{2}{|c|}{ Total } \\
\hline & $\%$ & $(\mathrm{~N})$ & $\%$ & $(\mathrm{~N})$ & $\%$ & $(\mathrm{~N})$ \\
\hline Fever & 51.6 & (869) & 48.4 & (814) & 100.0 & (1683) \\
\hline Cough & 51.6 & (986) & 48.4 & (925) & 100.0 & (1911) \\
\hline Diarrhea & 52.8 & (417) & 47.2 & (373) & 100.0 & (790) \\
\hline $\begin{array}{l}\text { Diarrhea } \\
\text { (within } 24 \text { hours) }\end{array}$ & 53.6 & (241) & 46.4 & (209) & 100.0 & $(450)$ \\
\hline $\begin{array}{l}\text { Treatment Given } \\
\text { (for fever, cough) }\end{array}$ & $52 \cdot 1$ & (868) & $47 \cdot 9$ & (799) & $100 \cdot 0$ & (1677) \\
\hline $\begin{array}{l}\text { Treatment Given } \\
\text { (for diarrhea) }\end{array}$ & $50 \cdot 1$ & (240) & $49 \cdot 9$ & (239) & $100 \cdot 0$ & (479) \\
\hline $\begin{array}{l}\text { ORS Given } \\
\text { (for diarrhea) }\end{array}$ & $52 \cdot 0$ & (173) & $48 \cdot 0$ & (160) & $100 \cdot 0$ & (333) \\
\hline
\end{tabular}

The pattern of such gender differences in sickness finds support from the findings of another UNICEF study [Ahmed (1990)], which shows higher proportions of male children recorded in various hospitals and health care units as sick with respiratory infections, diarrhea, and other diseases. One possible explanation given for these differences in morbidity is the mothers' greater likelihood of using bottlefeeding for male infants, perhaps because it is perceived as being superior to breastfeeding or as a source of providing their male children some extra and 
supplemental form of nutrition. ${ }^{2}$ However, evidence from the analysis of 38 DHS Surveys for 35 developing countries indicates that there is no significant association between sickness differentials and female mortality disadvantage [Hill and Upchurch (1994)].

In terms of the question of differentials in the treatment given to boys and girls during sickness, Table 3 shows a slight advantage to male children in terms of the treatment given for fever, cough, and diarrhea. But the absolute differences in percentages are quite small. For example, 52 percent of the boys were given ORS treatment for diarrhea as compared to 48 percent of the girls. A review of the records of patients brought for treatment in different health care units/hospitals, as undertaken in a UNICEF study, indicates a gender bias in favour of male children (see Appendix Table A). It appears that although parents' attitudes and perceptions about their child health are not gender-biased, their actual behaviour in terms of disease treatment has shown a bias in favour of male children. However, the study [Ahmed (1990)] concludes that there appears to be no strong gender bias in the areas of nutrition and health care when mothers are asked about taking care of the nutritional and health needs of their children.

\section{Use of Preventive Health Care}

Another factor that might account for the differences in child mortality is a gender differential in the use of preventive health care practices. The indicators of preventive measures used from the survey data are immunisation coverage of surviving children, child ever-breastfed, and the age at which solid or supplementary food was given to the child every day. Table 4 shows the percentages of girls and boys for these three indicators. It may be noted here that of the total surviving children, nearly 96 percent of the children are ever breastfed and about 58 percent received immunisation. Differences in immunisation coverage between boys and girls are of small magnitude ( 51 percent against 49 percent), which may be partly due to the extensive coverage given to the expanded programme of immunisation during the 1990s. There is some evidence that in certain places the girls being immunised actually exceeded the boys by a small percentage [Ahmed (1990)], implying effects of the heavy publicity campaign by the government and the strong outreach of the immunisation programme in recent years (see Appendix Table 2).

One area where gender differences are most neutralised is breastfeeding, a strong indicator of child nutrition and prevention from diarrheal sickness. Table 4 shows that almost equal proportions of girls and boys were breastfed. As for the intake of solid food by age of children, we find no difference in the proportions of boys and girls upto 12 months. For later ages of 1-4 years, the proportion of boys

\footnotetext{
${ }^{2}$ The PDHS data show that about one-quarter of the breastfed children under one year of age were given a bottle with a nipple the day before the interview [NIPS (1992)].
} 
given solid food regularly is higher (53 percent) than that of girls (47 percent). This difference may partially support the contention that boys get a preferential treatment in allocation of food relative to girls, an argument supporting the association between girls' nourishment and female mortality disadvantage during childhood (14 years).

Table 4

Use of Health-care Practices for Children (under five) by Gender: PDHS, 1990-91

\begin{tabular}{|c|c|c|c|c|c|c|}
\hline \multirow{2}{*}{$\begin{array}{l}\text { Health Care } \\
\text { Factors }\end{array}$} & \multicolumn{2}{|c|}{ Boys } & \multicolumn{2}{|c|}{ Girls } & \multicolumn{2}{|c|}{ Total } \\
\hline & $\%$ & $(\mathrm{~N})$ & $\%$ & $(\mathrm{~N})$ & $\%$ & $(\mathrm{~N})$ \\
\hline Child Immunised & $51 \cdot 2$ & (1381) & $48 \cdot 8$ & (1318) & $100 \cdot 0$ & (2699) \\
\hline $\begin{array}{c}\text { Child Ever- } \\
\text { breastfed }\end{array}$ & $50 \cdot 5$ & (2894) & 49.5 & (2837) & $100 \cdot 0$ & (5731) \\
\hline $\begin{array}{l}\text { Age at which Solic } \\
\text { Mushy Food } \\
\text { Given Daily }\end{array}$ & & & & & & \\
\hline$<6$ Months & 49.5 & (799) & $50 \cdot 5$ & (815) & $100 \cdot 0$ & (1614) \\
\hline 6-12 Months & $50 \cdot 0$ & (1187) & $50 \cdot 0$ & (1187) & $100 \cdot 0$ & (2374) \\
\hline $13+$ & $53 \cdot 0$ & (415) & $47 \cdot 0$ & (368) & $100 \cdot 0$ & 783 \\
\hline
\end{tabular}

The survey also collected information on the weight and height of children, making it possible to calculate anthropometric indices of nutritional status. Such indicators, in particular height for age, provide a good indication of the overall health status of children that is independent of mothers' perception. The PDHS report shows that nearly 30 percent to 50 percent of the children under five years of age are stunted, indicating chronic malnutrition (measured by height-for-age standard), and about 40 percent are classified as underweight (by weight-for-age standard). However, gender differences in these indices appear to be negligible and thus are not investigated in this paper. It may be noted here that the evidence for 35 DHS country reports indicates no significant association between stunting and wasting differentials by sex and female mortality disadvantage [Hill and Upchurch (1994)].

\section{CONCLUDING OBSERVATIONS}

An examination of past trends in infant and child mortality indicates that the overall levels of mortality have declined in Pakistan, even though the exact placement of the infant mortality rate is still questioned when viewed from different data sources.

The sex differentials in infant/child mortality still persist with more male deaths in the neonatal and infancy period, an age when genetic factors are more 
important in determining mortality risks, and a female disadvantage in child mortality, suggesting the importance of gender factors in girl mortality.

A simple comparison of the proportion dead by sex from the PDHS data suggests that boys experience the highest number of deaths in the first month of life. Greater risks of child death are experienced by younger, uneducated, and rural mothers. An association of these factors is found in the expected direction.

The data available to investigate the general hypothesis that sex differentials in childhood mortality reflect the discriminatory behaviour of parents against girls is limited. The simple and a preliminary analysis undertaken does not reflect any profound differences in child sickness and preventive and health care practice (at least as reported by mothers) in the PDHS data. Gender differences in health-related indicators are only weak, if at all related to gender differences in child mortality.

Among the health-related variables examined in this paper, some gender differences in diarrhea treatment and a slight difference in immunisation coverage are noted, both indicators significantly related to male-female mortality differentials (as is evident from Hill and Upchurch's analysis of 35 DHS reports of developing countries). This suggests that immunisation programmes are likely to be effective in reducing mortality in general, and that widespread outreach of immunisation and its publicity may be effective in reducing excess female mortality. However, the healthrelated variables we have used in this paper do not shed any light on the cultural and societal processes that contribute to the persistence of gender mortality differentials.

Nevertheless, gender differences in mortality appear to be associated clearly with one indicator which reflects the social status of women in society, i.e., the proportion of educated women. Our analysis does recommend increasing education for women and enhancing maternal and child health care facilities for younger mothers. In addition, the programmes aimed at reducing the leading causes of infant and child mortality such as acute respiratory diseases and diarrheal infections need to be improved. To achieve this end, educational campaigns for the promotion of breastfeeding and immunisation coverage appear to be important in the overall context of policy development.

This study has been limited to a small sample of the survey-children born during the five years preceding the survey-because health-related information is available only for these children. We feel that in order to capture the effects of sociocultural factors, which account for gender differences in health factors and their relation to child mortality differentials, much better and more specific data are required. The type of data we have used in this paper give us the relative differences in health care factors between boys and girls, but not the specific cultural values or attitudes that contribute to the existence of gender differences in the health and nutritional intake of children. 
$\frac{\sqrt[3]{3}}{\frac{2}{2}}$

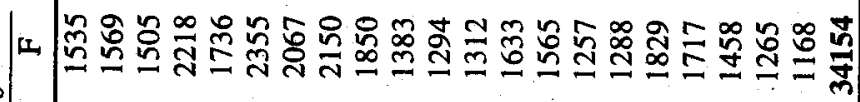

$+$

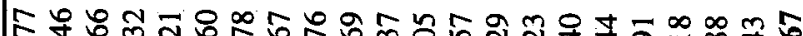
तิ

15

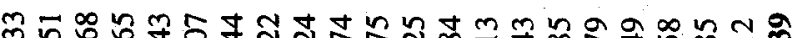

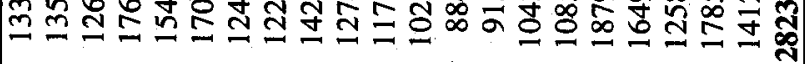

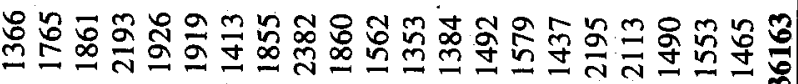

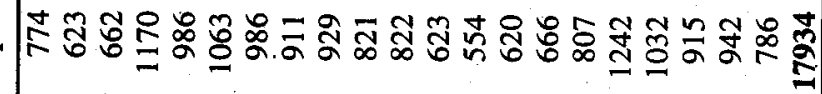

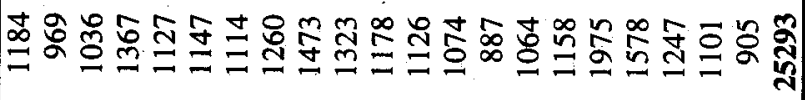

|幺

$\bar{d}$

次

泀 


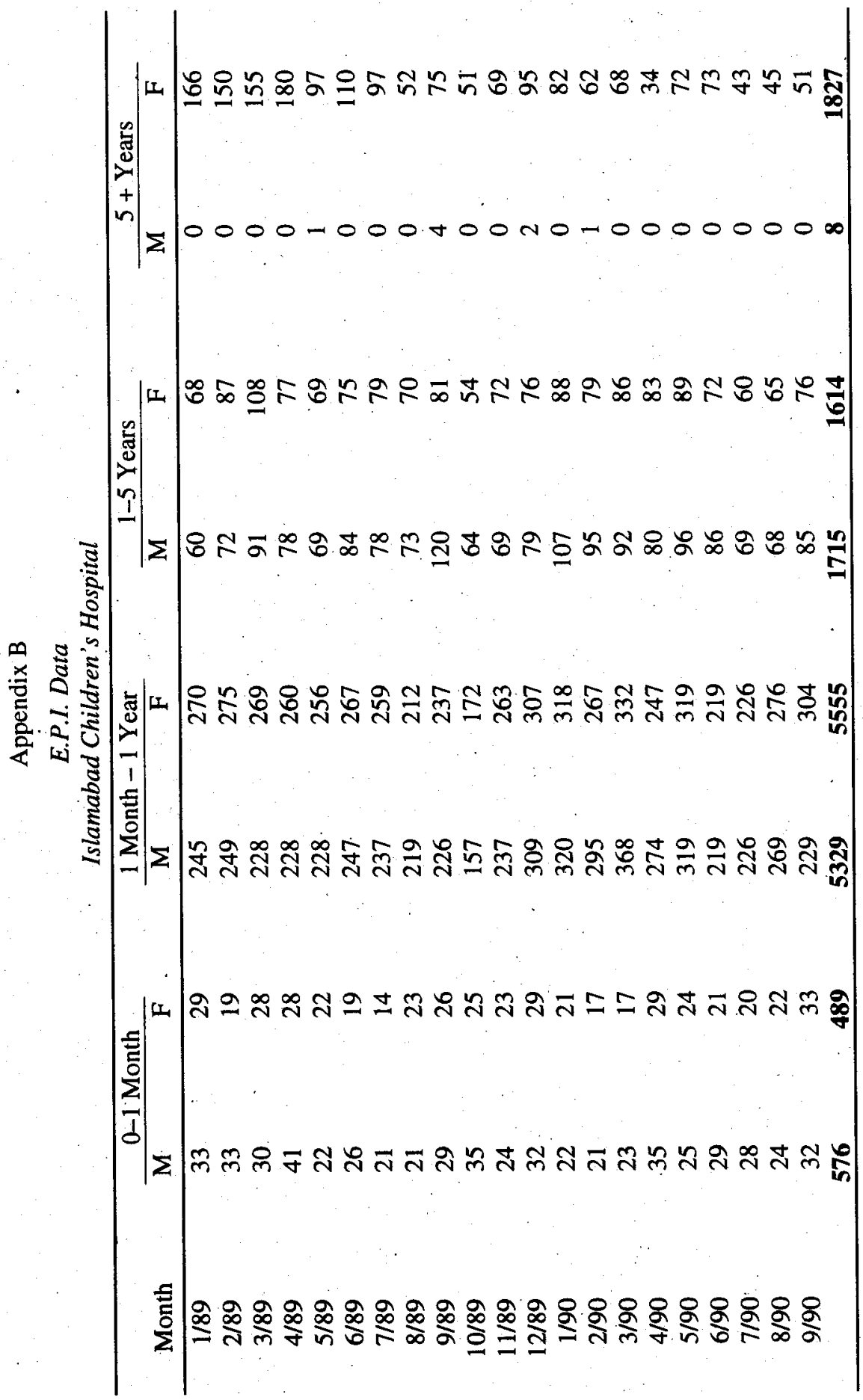




\section{REFERENCES}

Afzal, Mohammad, Tariq Aslam Raja, and Ali Mohammad (1988) Some Differentials in Infant and Child Mortality Risks in Pakistan: 1962-1986. The Pakistan Development Review 27:4 635-644.

Ahmed, Ambreen (1990) Gender Differentials in Access to Health Care for Pakistani Children. Study Conducted for UNICEF. Pakistan.

Ahmed, Tauseef (1992) Factors Associated with Child Mortality in Pakistan and Implications for the National Health Programmes. Asian and Pacific Population Forum. Honolulu, East-West Centre. 6:2.

Aslam, Iqbal, and John Cleland (1984) Infant and Child Mortality: Trends and Determinants. In Iqbal Alam and Betzy Divesen (eds) Fertility in Pakistan: A Review of Findings from PFS, 1975. Voorburg, The Netherlands: International Statistics Institute.

Alizai, Shagufta, and Asma Zia (1990) Gender Differentials in Access to Health Care for Pakistani Children. Study Conducted for UNICEF. Pakistan.

Chen, L., E. Huq, and S. D'Souza (1981) Sex Bias in the Family Allocation of Food and Health Care in Rural Bangladesh. Population and Development Review 7:1 $55-70$.

Das Gupta, Monica (1987) Selective Discrimination Against Female Children in Rural Punjab, India. Population and Development Review 13:1 77-100.

Lopez, A., and L. Ruzika (eds) (1983) Sex Differentials in Mortality. Canberra: Australian National University.

Mahmood, Naushin, and M. F. Kiani (1994) Health Care Determinants of Child Survival in Pakistan. The Pakistan Development Review 33:4 759-771.

Muhuri, Pradip K., and S. H. Preston (1991) Effects of Family Composition on Mortality Differentials by Sex among Children in Matlab, Bangladesh. Population and Development Review 17:3 415-434.

National Institute of Population Studies (1992) Pakistan Demographic and Health Survey 1990-1991. Columbia, MD: IBRD/Macro International.

Nill, Kenneth, and D. M. Upchurch (1994) Gender Differences in Child Health Status: Analysis of Demographic and Health Surveys. Paper presented at the 1994 Annual Meeting of the Population Association of America, Miami, Florida.

Pakistan, Government of (1986) National Health Survey, 1982-83. Karachi: Federal Bureau of Statistics, Statistics Division.

Porapakkam, Y. (1983) Case Studies of Sex Differences in the Utilisation of Health Resources in Thailand. In A. Lopez, and L. Puzicka (eds). Sex Differentials in Mortality. Canberra: Australian National University.

Sathar, Zeba A. (1987) Sex Differentials in Mortality: A Corollary of Son Preference. The Pakistan Development Review 26:4 555-565. 
Sathar, Zeba A. (1994) Infant Mortality in Pakistan: Uneven Risks in Urban and Rural Areas. Paper presented at the Agha Khan Workshop on Maternal and Infant Mortality-Policies and Interventions, Karachi, Feb. 7-9.

Waldron, Ingrid (1983) The Role of Genetic and Biological Factors in Sex Differences in Mortality. In A. Lopez, and L. Puzicka (eds) Sex Differentials in Mortality. Canberra: Australian National University. 